\title{
Hepatitis B surface antibodies seroprevalence among people born before and after implementation of universal HBV vaccination
}

\section{Federico A. Di Lello ${ }^{\mathrm{a} b, *}$, Jorgelina Blejer $^{\mathrm{c}}$, Adriana Alter ${ }^{\mathrm{c}}$, Sonia Bartoli ${ }^{\mathrm{d}}$, Fabiana Vargas ${ }^{\mathrm{e}}$, Rosángela Ruiz ${ }^{\mathrm{f}}$, Claudio Galli ${ }^{\text {f }}$, Sebastián Blanco ${ }^{\text {g,h }}$, Sandra Gallego ${ }^{\text {g,h }}{ }^{\text {, Roberto Fernández }}{ }^{\mathrm{c}}$, Alfredo P. Martínez ${ }^{\mathrm{i}}$, Diego M. Flichman ${ }^{\mathrm{b}, \mathrm{j}, *}$}

${ }^{a}$ Universidad de Buenos Aires, Facultad de Farmacia y Bioquímica, Instituto de Investigaciones en Bacteriología y Virología Molecular (IBaViM), Buenos Aires, Argentina

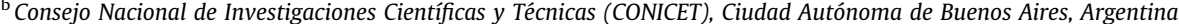

${ }^{\mathrm{c}}$ Fundación Hemocentro, Ciudad Autónoma de Buenos Aires, Argentina

d Centro Regional de Hemoterapia Jujuy, San Salvador de Jujuy, Jujuy, Argentina

${ }^{\text {e } C e n t r o ~ R e g i o n a l ~ d e ~ H e m o t e r a p i a ~ d e ~ M e n d o z a, ~ M e n d o z a, ~ M e n d o z a, ~ A r g e n t i n a ~}$

${ }^{\mathrm{f}}$ Hospital Regional Rio Grande, Rio Grande, Tierra del Fuego, Argentina

${ }^{\mathrm{g}}$ Facultad de Ciencias Médicas, Universidad Nacional de Córdoba, Córdoba, Córdoba, Argentina

${ }^{\mathrm{h}}$ Fundación Banco Central de Sangre, Córdoba, Córdoba, Argentina

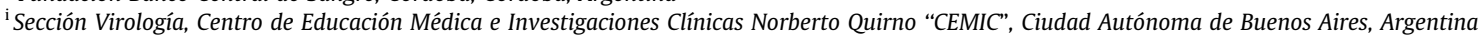

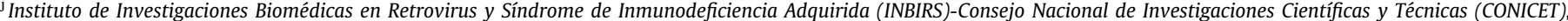
Universidad de Buenos Aires, Ciudad Autónoma de Buenos Aires, Argentina

\section{A R T I C L E I N F O}

\section{Article history:}

Received 30 September 2019

Received in revised form 22 January 2020

Accepted 5 February 2020

Available online 13 February 2020

Keywords:

Hepatitis B virus

Vaccine

Anti-HBs titers

\begin{abstract}
A B S T R A C T
Universal vaccination is the most effective strategy to control hepatitis B virus (HBV) infection. In Argentina, vaccination against HBV was incorporated in year 2000 for newborns and in 2003 for 11 years old children. However, there is a paucity of data about protection levels against HBV infection.

The aim of this work was to determine the prevalence of seroprotective anti-HBs antibodies (aHBs) in Argentina.

Serum samples negative for HBsAg and anti-HBc from 132 children born after year 2000 and 762 blood donors, older than 18 years, from five centers across the country, were analyzed for aHBs.

Titers $\geq 10 \mathrm{mIU} / \mathrm{mL}$ were observed in $74 / 132$ children (56.1\%) and 336/762 (44.1\%) in blood donors. The median age for blood donors was 33.9 (23-43); from them, 210 (27.6\%) were born after 1992 and, therefore, were catch-up by vaccine implementation at 11 years old age. Donors born in 1992 or before showed a significantly lower frequency of protection (32.2\%) compared to donors born after 1992 (75.2\%), $\mathrm{p}<0.0001$. In addition, significant differences were observed in the status of seroprotection between different participating centers $(\mathrm{p}=0.024)$.

Implementation of HBV vaccine in 2000 and 2003 implied an overall increase of the aHBs seroprotective rates, with a particularly adequate response in children vaccinated at 11 years old age. The observed results suggest that population born in 1992 or before is currently the most susceptible. Consequently, it would be advisable to become aware of the risk of transmission in this age group and to stress this population vaccination campaigns.
\end{abstract}

(c) 2020 Elsevier Ltd. All rights reserved.

\footnotetext{
* Corresponding authors at: Facultad de Farmacia y Bioquímica, Universidad de Buenos Aires, Junín 956, 4 piso, (1113), Ciudad Autónoma de Buenos Aires, Argentina (F. Alejandro). Instituto de Investigaciones Biomédicas en Retrovirus y Síndrome de Inmunodeficiencia Adquirida (INBIRS). Ciudad Autónoma de Buenos Aires, Argentina (D.M. Flichman).

E-mail addresses: fadilello@ffyb.uba.ar (F.A. Di Lello), dflichman@ffyb.uba.ar (D.M. Flichman)
}

\section{Introduction}

Hepatitis B virus (HBV) infection and HBV-related complications remain as a major global public health problem [1]. Approximately 260 million people are chronically infected and almost 1 million deaths occur yearly, most of them from complications including cirrhosis and hepatocellular carcinoma [2].

In Argentina, the estimated prevalence of HBV infection in blood donors is $1-2 \%$ with an uneven distribution in different 
regions around the country [3]; the infection rate in patients aged $15-24$ years old is 1.14 per 100,000 [4]. In addition, prenuptial studies carried out in four Argentine urban conglomerates during 2013 and 2014 showed an HBsAg prevalence of $0.26 \%$ [5].

Although Argentina is considered a low prevalence country, chronic HBV infection has been the leading cause of fulminant hepatitis and the third cause of liver transplantation in the 2005-2011 period [6,7]. Moreover, a latest study reported an unexpected high frequency of recent infections in the blood donor population [8]. Thus, despite treatment and prevention great progresses, HBV infection is still a main health problem both globally and regionally.

HBV vaccine was introduced in the early 80 s and the global coverage with the complete scheme of doses is currently estimated to be higher than $80 \%[2,9]$. In Argentina, vaccination was sequentially implemented: initially, in 1992, for health working personnel and recommended for groups with risk behaviors (National Law No. 24.151); then, in 2000, in the National Vaccination Calendar for newborns (Res. 940/00); and later, in 2003, for 11-year-old children (Res. 175/03). Although through these interventions HBV infection rates decreased among children, the incidence of viral infection did not declined significantly in the adolescent and adult population [10]. For this reason, in 2012, the hepatitis B vaccine was incorporated for adults in Argentina. Consequently, children born after 2000 have been covered by the newborn mandatory vaccination and those born between 1992 and 2000 received the vaccine when they reached the age of 11 years old. According to World Health Organization (WHO) estimates, the Argentine vaccine coverage should be higher than $80 \%$ for people born after 1992 [2]. Regardless of these estimates, there is a paucity of accurate data concerning the protection state for HBV in the Argentine population. Moreover, according to data from the Argentine Ministry of Health, incidence of HBV in children has decreased in the last decade probably due to universal immunization campaigns. However, most cases of HBV infection come from people older than 35 years old [11], age group that is in coincidence with persons not reached at the beginning of the mandatory vaccine period. Additionally, the Argentine average age of acute HBV infections is 44 years old, also in coincidence with the age group not reached by the vaccine incorporation to the calendar [12]. Therefore, at present, people born before year 1992 seems to be the main vulnerable population to HBV infection in the country. However, there is no data regarding immunoprotection for HBV in individuals born after year 1992, and none local study has addressed this issue until now.

For this reason, the aim of this work was to determine and compare the level of immune protection against HBV in population from different regions from Argentina, born before and after the incorporation of universal HBV vaccination.

\section{Materials and methods}

\subsection{Study population}

Serum samples negative for anti-HBc and HBsAg from 894 individuals were included in this study. On the one hand, 132 samples from under 18 children reached by the 2000 vaccine implementation, who attended a Hospital in Buenos Aires, were retrospectively collected from June 2013 until December 2018. On the other hand, 762 samples from individuals who attended five blood donor centers located in the North, South, Central, East and West regions from Argentina were prospectively collected from February 2019 until May 2019.

This sample group included 210 individuals born after 1992 and reached by the 11-year-old children vaccine implementation in 2003, and 552 individuals born in 1992 or before, not reached by the vaccine implementation. Blood donors who were health workers were excluded from the study sample. All participants signed an informed consent.

\subsection{Laboratory determinations}

Sera were separated and frozen at $-20{ }^{\circ} \mathrm{C}$ until testing. HBV serological markers aHBc, aHBs and $\mathrm{HBsAg}$ were analyzed with Architect Abbott system; Abbott Diagnostics, Wiesbaden, Germany. All tests were carried out following the manufacturer's instructions.

\subsection{Statistical analysis}

Frequencies were compared using the chi-square test or the Fisher's test. The Student's t-test and the Mann-Whitney U were used for comparing continuous variables. In order to identify predictors of seroprotective status in the analyzed population, a logistic regression analysis adjusted for age and sex was performed. Factors associated to seroprotective status in the bivariate analysis with a $\mathrm{p}$ value $\leq 0.2$ were entered as covariates. The statistical analysis was carried out using the SPSS statistical software package release 19.0 (IBM SPSS Inc., Chicago, IL, USA).

\section{Results}

\subsection{Population characteristics}

One hundred thirty-two children born after 2000 and negative for anti-HBc and HBsAg were included in the study, 69 (52.3\%) were female and the median age (Q1-Q3) was 10 (5-15) years.

Moreover, samples from 762 blood donors negative for anti-HBc and HBsAg were analyzed. Their median (Q1-Q3) age was 34 (27$43)$ years old and 305 (40.0\%) were female. Women were one year older than men were [34 (27-43) vs. 33 (27-43), respectively $\mathrm{p}=0.016]$. Table 1 summarizes the study population characteristics by age group.

\section{2. aHBs status}

From 132 children, 74 (56.1\%) have aHBs titers $\geq 10 \mathrm{mIU} / \mathrm{mL}$. There were no significant differences in the rate of seroprotection by gender [37 (53.6\%) for female and 37 (58.7\%) for male, $\mathrm{p}=0.555$ ]. Interestingly, aHBs coverage rate in 1 to 5 years old children $(87.5 \%)$ was significantly higher compared to those between 6 and 17 years old $(46.0 \%)$ ( $\mathrm{p}<0.001)$.

As regards blood donors, 336 (44.1\%) showed seroprotective titers. Rates were significantly higher in women than in men (50.8\% vs. $39.6 \%$, respectively $\mathrm{p}=0.003$ ).

\subsection{Association between year of birth and aHBs status in blood donors}

There was a significant bias in aHBs protective prevalence according to whether blood donors were reached or not by the implementation of the vaccine in the national schedule. In individuals born after 1992 (reached by the 2003 vaccination program), aHBs seroprotection rates were significantly higher than in individuals born in 1992 or before $(75.2 \%$ vs. $32.2 \%$, respectively $\mathrm{p}<0.0001$ ) (Table 2). When the studied population was separated by gender, there were no significant differences in seroprotection frequencies between men and women born after 1992 [86 (72.3\%) vs. 72 (79.1\%), respectively $\mathrm{p}=0.254$ ]. However, significant differences were found between men and women born in 1992 or before [95 (28.1\%) vs. 83 (38.8\%), respectively $\mathrm{p}=0.009$ ]. 
Table 1

Blood donors characteristics by age group $(\mathrm{N}=894)$.

\begin{tabular}{|c|c|c|c|c|}
\hline Age group & Children (born before 2000) & Blood donors (born before 1992) & Blood donors (born after 1992) & $\mathrm{P}^{\mathrm{a}}$ \\
\hline $\mathrm{N}$ & 132 & 552 & 210 & \\
\hline Age Median (IQR) & $10(5-15)$ & $38(32-46)$ & $24(21-26)$ & - \\
\hline $\begin{array}{l}\text { By gender } \\
\text { Female } \\
\text { Male }\end{array}$ & $\begin{array}{l}69(52.3) \\
63(47.7)\end{array}$ & $\begin{array}{l}214(38.8) \\
338(61.2)\end{array}$ & $\begin{array}{l}91(43.3) \\
119(56.7)\end{array}$ & 0.250 \\
\hline $\begin{array}{l}\text { By region } \\
\text { East (\%) } \\
\text { Center (\%) } \\
\text { North (\%) } \\
\text { West (\%) } \\
\text { South (\%) }\end{array}$ & $\begin{array}{l}\text { na } \\
\text { na } \\
\text { na } \\
\text { na } \\
\text { na }\end{array}$ & $\begin{array}{l}124(77.5) \\
107(71.8) \\
91(61.5) \\
109(72.7) \\
121(78.1)\end{array}$ & $\begin{array}{l}36(22.5) \\
42(28.2) \\
57(38.5) \\
41(27.3) \\
34(21.9)\end{array}$ & 0.009 \\
\hline
\end{tabular}

na: Not applicable.

a. Comparison of blood donors born before or after 1992.

Table 2

Protective levels of aHBs ( $\geq 10 \mathrm{mIU} / \mathrm{ml})$ by age group $(\mathrm{N}=894)$.

\begin{tabular}{|c|c|c|c|c|}
\hline Age group & Children (born before 2000) & Blood donors (born before 1992) & Blood donors (born after 1992) & $\mathrm{P}^{\mathrm{a}}$ \\
\hline $\mathrm{N}$ & 132 & 552 & 210 & \\
\hline $\begin{array}{l}\text { aHBs titer } \\
\quad \geq 10 \mathrm{mIU} / \mathrm{ml}(\%)\end{array}$ & $74(56.1)$ & $178(32.2)$ & $158(75.2)$ & $<0.001$ \\
\hline \multicolumn{5}{|l|}{ By Gender } \\
\hline Female (\%) & $37(53.6)$ & $83(38.8)$ & $72(79.1)$ & $<0.001$ \\
\hline Male (\%) & $37(58.7)$ & $95(28.1)$ & $86(72.3)$ & $<0.001$ \\
\hline \multicolumn{5}{|l|}{ By region } \\
\hline East (\%) & na & $39(31.5)$ & $23(63.9)$ & $<0.001$ \\
\hline Center (\%) & na & $21(19.6)$ & $33(78.6)$ & $<0.001$ \\
\hline North (\%) & na & $30(33.0)$ & $48(84.2)$ & $<0.001$ \\
\hline West (\%) & na & $39(35.8)$ & $28(68.3)$ & $<0.001$ \\
\hline South (\%) & na & $49(40.5)$ & $26(76.5)$ & $<0.001$ \\
\hline
\end{tabular}

na: Not applicable.

a. Comparison of blood donors born before or after 1992 .

In addition, there were significant differences in aHBs $\geq 10 \mathrm{mIU} /$ $\mathrm{mL}$ rates between children and adults born in 1992 or before ( $56.1 \%$ vs. $32.2 \%, \mathrm{p}<0.001$, respectively) as well as among children reached by vaccination since year 2000, and adults born after 1992 reached by the vaccine implementation since 2003 (56.1\% vs. $75.2 \%, \mathrm{p}<0.001$, respectively).

In a multivariate analysis adjusted by gender, year of birth and country region, women and people born after 1992 showed higher seroprotection frequencies [OR $1.68(1.21-2.32) \mathrm{p}=0.002$ and 6.55 (4.53-9.49) p < 0.0001, respectively]. In addition, the East and Central regions showed lower seroprotective levels than the South region. Results of the univariate and multivariate analyses are shown in Table 3.

\section{Discussion}

WHO has stated different goals that should contribute to eliminate hepatitis $B$ as a public health threat. The main objective includes the universal vaccination, which is the most effective strategy to achieve a decrease in HBV transmission.

Two strategies allow to supervising the effectiveness of vaccination plans: on the one hand, the estimation of vaccination coverage rate and, on the other hand, the advisable evaluation of population aHBs prevalence. This approach would permit to identify vaccination campaigns achievements and limitations as well as to recognize the drawbacks in order to focus the resources destination according to needs.

Table 3

Univariate and multivariate analysis to assess the parameters associated to aHBs $\geq 10 \mathrm{mIU} / \mathrm{mL}$ in the donor population ( $\mathrm{N}=762$ ).

\begin{tabular}{|c|c|c|c|c|c|}
\hline Parameter & $\mathrm{N}(\%)$ & aHBs $\geq 10, \mathrm{n}(\%)$ & $p$ uni-variate & AOR $(95 \% \mathrm{CI})$ & $p$ multi-variate \\
\hline \multicolumn{6}{|l|}{ Gender } \\
\hline Female & $305(40)$ & $155(50.8)$ & 0.003 & $1.68(1.21-2.32)$ & 0.002 \\
\hline Male & $457(60)$ & $181(39.6)$ & & 1 & \\
\hline \multicolumn{6}{|l|}{ Year of birth } \\
\hline After1992 & $210(27.6)$ & $158(75.2)$ & $<0.001$ & $6.55(4.53-9.49)$ & $<0.001$ \\
\hline 1992 or before & $552(72.4)$ & $178(32.3)$ & & 1 & \\
\hline \multicolumn{6}{|l|}{ Region } \\
\hline East & $160(21)$ & $62(38.7)$ & 0.024 & $0.59(037-0.97)$ & 0.037 \\
\hline Central & 149 (19.6) & $54(36.2)$ & & $0.45(0.27-0.74)$ & 0.002 \\
\hline North & $148(19.4)$ & $78(52.7)$ & & $0.83(0.50-1.36)$ & 0.459 \\
\hline West & $150(19.7)$ & $67(44.6)$ & & $0.68(0.41-1.11)$ & 0.124 \\
\hline South & $155(20.3)$ & $75(48.4)$ & & 1 & 0.001 \\
\hline
\end{tabular}

AOR: adjusted odds ratio; $\mathrm{CI}$ : confidence interval. 
To our knowledge, this is the first study estimating the seroprotection rates against HBV infection, through aHBs titers, in a representative size cohort from Argentina. Overall the seroprotection levels were lower than the expected ones [2], being suitable for the population born between years 1992 and 2000, intermediate for the population reached by universal newborn vaccination since year 2000, and scarce for people born before 1992. Routine childhood immunization against hepatitis B, according to WHO, has increased globally with an estimated complete scheme coverage of $84 \%$ in 2017 [2]. Individuals reached by the implementation of the vaccine, either at birth (born after 2000) or catch-up at 11 years old (born after 1992), showed an increase in the rate of protective titers, in line with the coverage rate of the vaccine against HBV estimated by the Argentine Ministry of Health and WHO [2,9].

The lower frequency of protective titers of aHBs in children vaccinated at birth compared to those vaccinated at the 11 years old age may be a consequence, as previously described, to a rapid decrease of antibody levels observed in the former group [1317]. In fact, children between 1 and 5 years old, more recently vaccinated, have shown significant higher coverage rates than those aged 6-17 years old. Likewise, children born after the year 2000, vaccinated at birth, have shown a higher frequency $(24.2 \%)$ of low antibody levels (1-9.99 $\mathrm{mIU} / \mathrm{mL}$ ), compared to those vaccinated at the age of 11 years old $(9.8 \%)$.

Other reasons, in addition to age at the time of vaccination, whereby children vaccinated at born showed titers between 1 and $9.99 \mathrm{mIU} / \mathrm{mL}$ could be an incomplete vaccination schedule or the application of a pentavalent vaccine formulation, which may induce low and uneven aHBs titers [18].

The decrease in anti-HBs antibodies over time below the seroprotection threshold is a controversial issue. Several studies have shown that individuals with aHBs levels between 1 and 9.99 $\mathrm{mIU} / \mathrm{mL}$ quickly recover seroprotective aHBs levels after receiving a booster [19-22], due to immune memory $[23,24]$. In this context, the available bibliography widely reports that individuals with aHBs levels between 1 and $9.99 \mathrm{mIU} / \mathrm{mL}$ mostly generate an adequate anamnestic response and, therefore, are considered protected against HBV infection [25-27]. Consequently, the WHO does not recommend booster vaccination in successfully immunized individuals $[2,28]$.

Although the donor cohort born after 1992 showed no differences in the seroprotection rate due to gender or geographic region, in donors born in 1992 or before, seroprotection rate was significantly lower in the central region and in men. Levels of vaccine coverage variation among regions, in the cohort born in 1992 or before, may be due to demographic differences as well as to the strength of campaigns and public awareness. Differences in coverage rates according to gender could be the consequence of a greater awareness of the female population as they have a closer medical control, especially in fertile age.

The low rates of protective aHBs detected in people born in 1992 or before highlight the limited success for the initiative of adult vaccination promoted in year 2012 to strengthen the control and elimination of HBV in Argentina. This pitfall is in line with the high frequency of HBV recent infections observed in blood donor population, and the average age of persons diagnosed with acute HBV infections $[8,12]$.

\section{Conclusion}

The implementation of the HBV vaccine in the Argentine national calendar meant a significant increase in the population's seroprotection rate, which shows the effectiveness of universal vaccination, either at birth or in adolescence.

In 2016, World Health Assembly has adopted the Global Health Sector Strategy on viral hepatitis to eliminate hepatitis by 2030
[29]. The low rate of protective aHBs titers of individuals born in 1992 or before observed in this study, highlight the necessity to emphasize health measures pointed to this cohort, in order to achieve the desired control of HBV transmission. Finally, these study findings contribute to the national public health system planning and are useful to control and evaluate the effectiveness of vaccination plans and campaigns, as well as to guide future HBV immunization programs in our country.

\section{CRediT authorship contribution statement}

FAD, DMF: Conceptualization, Data curation, Formal analysis, Funding acquisition, Investigation, Methodology, Supervision, Validation, Writing - original draft, Writing - review \& editing. JB, AA, SB, FV, RR, CG, SB, SG, RF, APM: Data curation, Formal analysis, Methodology, Validation and Writing - original draft.

\section{Declaration of Competing Interest}

The authors declare that they have no known competing financial interests or personal relationships that could have appeared to influence the work reported in this paper.

\section{Acknowledgments}

F.A.D. and D.M.F. are members of the Consejo Nacional de Investigaciones Científicas y Técnicas (CONICET) Research Career Program. Grant from Fundación Alberto J. Roemmers. We would like to thank to Mrs. Silvina Heisecke for providing language assistance.

\section{Ethical approval and informed consent}

The study protocol was approved by the ethics committee from "Facultad de Farmacia y Bioquímica, Universidad de Buenos Aires" (record number 02032015-2/2015) in accordance with the 1975 Helsinki Declaration. Written informed consents to participate in this study were obtained from all individuals.

\section{References}

[1] Schweitzer A, Horn J, Mikolajczyk RT, et al. Estimations of worldwide prevalence of chronic hepatitis B virus infection: a systematic review of data published between 1965 and 2013. Lancet 2015;386:1546-55.

[2] World Health Organization, Hepatitis B. http://www.who.int/news-room/factsheets/detail/hepatitis-b [Accessed July 2019].

[3] Flichman DM, Blejer JL, Livellara BI, et al, Prevalence and trends of markers of hepatitis B virus, hepatitis C virus and human immunodeficiency virus in Argentine blood donors. BMC Infect Dis 2014;14:218.

[4] http://www.msal.gob.ar/images/stories/ryc/graficos/0000000865cnt-2014 09 estado-hepatitis-virales-argentina.pdf [Accessed July 2019].

[5] https://www.paho.org/arg/images/gallery/Sifilis\%20y\%20hepatitis.pdf [Accessed July 2019].

[6] Fassio E, Míguez C, Soria S, et al. Etiology of hepatocellular carcinoma in Argentina: results of a multicenter retrospective study. Acta Gastroenterol Latinoam 2009;39:47-52.

[7] Mendizabal M, Marciano S, Videla MG, et al. Changing etiologies and outcomes of acute liver failure: perspectives from 6 transplant centers in Argentina. Liver Transpl 2014;20:483-9.

[8] Blanco S, Balangero MC, Valle MC, et al. Usefulness of nucleic acid testing to reduce risk of hepatitis B virus transfusion-transmitted infection in Argentina: high rate of recent infections. Transfusion 2017;57:816-22.

[9] Cassidy A, Mossman S, Olivieri A, et al. Hepatitis B vaccine effectiveness in the face of global HBV genotype diversity. Expert Rev Vacc 2011;10:1709-15.

[10] http://www.msal.gob.ar/images/stories/bes/graficos/0000000446cnt-201310_lineamientos-vacunacion-universal-hepatitis-b.pdf [accessed July 2019].

[11] http://www.msal.gob.ar/images/stories/bes/graficos/0000001400cnt-201901 respuesta-hepatitis-virales.pdf [Accessed July 2019].

[12] Marciano S, Flichman DM, Trinks J, et al. Risk factors for progression to chronic hepatitis in patients with acute hepatitis B: results from the acute Hepatitis B Global Study. XXV Congreso de la Asociación Latinoamericana para el Estudio del Hígado (ALHE), 2018.

[13] Dini G, Toletone A, Barberis I, et al. Persistence of protective anti-HBs antibody levels and anamnestic response to HBV booster vaccination: a cross-sectional 
study among healthcare students 20 years following the universal immunization campaign in Italy. Hum Vaccin Immunother 2017;13:440-4.

[14] Bianchi FP, Gallone MS, Gallone MF, et al. HBV seroprevalence after 25 years of universal mass vaccination and management of non-responders to the antiHepatitis B vaccine: an Italian study among medical students. J Viral Hepat 2019;26:136-44.

[15] Boxall EH, Sira J, El-Shuhkri N, et al. Long-term persistence of immunity to hepatitis B after vaccination during infancy in a country where endemicity is low. J Infect Dis 2004;190:1264-9.

[16] Pollard AJ, Perrett KP, Beverley PC. Maintaining protection against invasive bacteria with protein-polysaccharide conjugate vaccines. NatRev Immunol 2009;9:213-20.

[17] Chiara F, Bartolucci GB, Cattai M, et al. Hepatitis B vaccination of adolescents: significance of non-protective antibodies. Vaccine 2013;32:62-8.

[18] Evdokimov K, Sayasinh K, Nouanthong P, et al. Low and disparate seroprotection after pentavalent childhood vaccination in the Lao People's Democratic Republic: a cross-sectional study. Clin Microbiol Infect 2017;23:197-202.

[19] Klinger G, Chodick G, Levy I. Long-term immunity to hepatitis B following vaccination in infancy: real-world data analysis. Vaccine 2018;36:2288-92.

[20] Coppeta L, Pompei A, Balbi O, et al. Persistence of immunity for hepatitis B virus among heathcare workers and Italian Medical students 20 years after vaccination. Int J Environ Res Public Health 2019;16:(9).

[21] Wu Z, Yao J, Bao H, et al. The effects of booster vaccination of hepatitis B vaccine on children 5-15 years after primary immunization: a 5-year followup study. Hum Vaccin Immunother 2018;14(5):1251-6.
[22] Zhao YL, Han BH, Zhang XJ, et al. Immune persistence 17 to 20 years after primary vaccination with recombination hepatitis $\mathrm{B}$ vaccine $(\mathrm{CHO})$ and the effect of booster dose vaccination. BMC Infect Dis 2019;19(1):482. https://doi. org/10.1186/s12879-019-4134-9.

[23] Leuridan E, Van Damme P. Hepatitis B and the need for a booster dose. Clin Infect Dis 2011;53:68-75.

[24] Bruce MG, Bruden D, Hurlburt D, et al. Antibody levels and protection afte hepatitis B vaccine: results of a 30-year follow-up study and response to a booster dose. J Infect Dis 2016;214:16-22.

[25] Williams IT, Goldstein ST, Tufa J, et al. Long term antibody response to hepatitis B vaccination beginning at birth and to subsequent booster vaccination. Pediatr Infect Dis J 2003;22:157-63.

[26] Mendy M, Peterson I, Hossin S, et al. Observational study of vaccine efficacy 24 years after the start of hepatitis B vaccination in two Gambian villages: no need for a booster dose. PLoS ONE 2013;8:e58029.

[27] Coppola N, Corvino AR, De Pascalis S, et al. The long-term immunogenicity of recombinant hepatitis $B$ virus (HBV) vaccine: contribution of universal HBV vaccination in Italy. BMC Infect Dis 2015;15:149.

[28] Simms KT, Smith MA, Caruana M, et al. A hepatitis B vaccine booster shot at age 10 could be cost-saving in China: but is it too soon to tell?. Int J Infect Dis 2019;78:128-9. https://doi.org/10.1016/j.ijid.2018.11.007 [Epub 2018 Nov $15]$.

[29] World Health Organization. Global Health Sector Strategies on Viral Hepatitis 2016-2021. Available from: http://apps.who.int/gb/ebwha/pdf_files/WHA69/ A69_32-en.pdf?ua=1. 